\title{
Characterisation and categorisation of the diversity in viscoelastic vibrational properties between 98 wood types
}

\author{
Iris Brémaud • Yves El Kaïm • Daniel Guibal • \\ Kazuya Minato $\cdot$ Bernard Thibaut $\cdot$ Joseph Gril
}

Received: 18 August 2011 / Accepted: 15 November 2011 /Published online: 9 December 2011

(C) INRA / Springer-Verlag France 2011

\begin{abstract}
- Context Increased knowledge on diversity in wood properties would have implications both for fundamental research and for promoting a diversification of uses as material.

- Aims The objective is to contribute to overcoming the critical lack of data on the diversity of wood dynamic mechanical/viscoelastic vibrational properties by testing lesser known species and categorising sources of variability.
\end{abstract}

Handling Editor: Barry Alan Gardiner

Contribution of co-authors I.B. designed and performed research and wrote the paper; Y.E.K. realized test device II and control/ processing software; D.G. did physical tests; K.M. initiated the methodology; K.M., B.T. and J.G. supervised the work and edited the paper.

I. Brémaud · Y. El Kaïm • B. Thibaut · J. Gril

Laboratoire de Mécanique et Génie Civil (LMGC), CNRS,

Université Montpellier 2, Place E. Bataillon, cc 048, 34095

Montpellier cedex 5, France

I. Brémaud $\cdot$ K. Minato

Laboratory of Forest Resources Circulatory System,

Kyoto Prefectural University,

Kyoto 606-8522, Japan

D. Guibal

UPR Production et Valorisation des Bois Tropicaux et

Méditerranéens, CIRAD,

BP 5035, 34398 Montpellier cedex 5, France

B. Thibaut

UMR Ecologie des Forêts de Guyane, CNRS,

BP 316-97379 Kourou cedex, French Guyana, France

Present Address:

I. Brémaud $(\bowtie)$

Wood Laboratory, EMPA,

Überlandstrasse 129, 8600 Dübendorf, Switzerland

e-mail: iris_bremaud@hotmail.com
- Methods Air-dry axial specific dynamic modulus of elasticity $\left(E^{\prime} / \gamma\right)$ and damping coefficient $(\tan \delta)$ were measured on a wide sampling (1,792 specimens) of 98 wood types from 79 species. An experimental device and protocol was designed for conducting systematic (i.e. rapid and reproducible) characterisations.

- Results Diversity at the specimens' level corroborates the "standard" relationship between $\tan \delta$ and $E^{\prime} / \gamma$, which is discussed in terms of orientation of wood elements and of chemical composition. Diversity at the species level is expressed on the basis of results for normal heartwood, with specific gravity $(\gamma)$ ranging from 0.2 to 1.3 . Axial $E^{\prime} / \gamma$ ranges from 9 to $32 \mathrm{GPa}$ and $\tan \delta$ from $4 \times 10^{-3}$ to $19 \times 10^{-3}$. Properties distribution follows a continuum, but with group characteristics. The lowest values of $\tan \delta$ are only found in certain tropical hardwoods. Results can also suggest alternative species for musical instruments making.

- Conclusion The variations in specific gravity, in stiffness or in "viscosity" appear to be predominantly linked to different levels of diversity: between species or between wood types (reaction wood or taxonomy-related differences in heartwood extractives).

Keywords Damping coefficient · Dynamic mechanical properties - Specific dynamic modulus of elasticity - Specific gravity - Viscoelastic vibrational properties - Wood diversity

\section{Introduction}

Exploring the diversity of wood properties has long been a goal of foresters and wood technologists and more recently has found implications in research into functional ecology and biomechanics (e.g. Chave et al. 2009). Large databases of physico-mechanical properties can also contribute to a 
physical understanding of traditional preferences for specific woods in various cultural uses (Brémaud 2012). They are also the pre-requisite for applying material selection methods (e.g. Wegst 2006), which could allow more efficient, diversified and potentially sustainable utilisation of wood materials. Amongst the 50,000+ wood-producing species, data are available for a proportionally moderate, yet quite important number of species for some properties: at least 8,000 species for specific gravity or density (e.g. Détienne and Chanson 1996; Chave et al. 2009), a minimum of 1,0002,000 species for the longitudinal modulus of elasticity (unpublished database at CIRAD; many other wood technology resources). Unfortunately, there is still a critical lack of knowledge on the diversity of some other relevant properties, notably concerning anisotropy and viscoelasticity. An up-todate census on most published data on viscoelastic vibrational properties reveals that $\leq 400$ species have been characterised, even partially (Brémaud et al. 2009; Brémaud 2012).

The diversity in wood properties expresses variations in structure (cellular and sub-cellular) and chemical composition (constitutive polymers and secondary metabolites). For wood along the grain, cellular anatomy mostly intervenes in the sense of "porosity", i.e. it determines specific gravity $(\gamma)$ and thus affects Young's modulus $(E)$. On the contrary, vibrational properties (specific dynamic modulus of elasticity $=E^{\prime} / \gamma$ and damping coefficient $=\tan \delta$ ) are primarily governed at the cell-wall level, with $E^{\prime} / \gamma$ decreasing, and $\tan \delta$ increasing, with increasing microfibril angle (Obataya et al. 2000). As a result, a strong relationship generally exists between $\tan \delta$ and $E^{\prime} / \gamma$ (Ono and Norimoto 1983, 1984). Variations in grain angle have similar impacts on both properties and result in a comparable $\tan \delta-E^{\prime} / \gamma$ relationship (Brémaud et al. 2010a, 2011b). Futhermore, the composition of the "matrix" of hemicelluloses and lignin determines the viscous behaviour (Obataya et al. 2000; Olsson and Salmén 1992, 1997). Some extractive compounds can also play a key role in modifying $\tan \delta$, by as much as a factor 2, with only minor effects on $E^{\prime} / \gamma$ (Yano 1994; Matsunaga et al. 1996; Obataya et al. 1999; Minato et al. 2010; Brémaud et al. 2010b, 2011a).

Anatomical and chemical features can be related to or even be characteristic of various levels of diversity, from plant order to species, and also be related to biogeography. Softwoods generally have a simpler anatomy and a higher content of lignin, which also has a more condensed chemical structure (Olsson and Salmén 1992, 1997). Amongst hardwoods, tropical ones show more diversity and often some typical features such as interlocked grain or high extractives content (EC) (e.g. Hernandez 2007; Brémaud et al. 2010a,b). Cellular anatomy and secondary metabolites can be particularly characteristic of a genus or even a species. In addition to species diversity, there is a wide within-species variability, between or within trees, between different wood types, e.g. "normal" versus reaction wood (variations in both anatomy and polymers), or heartwood versus sapwood (variations in extractives but similar anatomy and constitutive polymers).

The exploration and analysis of the diversity in wood properties requires obtaining very large datasets. A few long-term studies using the same methodology exist (e.g. Détienne and Chanson 1996; unpublished CIRAD database and other research institutes resources). In order to compare a maximum of species, however, results from different sources have to be compiled (e.g. Chave et al. 2009; Brémaud et al. 2009). This efficient approach has nevertheless drawbacks: even in the case of "simple" properties such as specific gravity or density, comparison of data obtained by different methodologies can be misleading (Williamson and Wiemann 2010). For viscoelastic vibrational properties, many sources (mainly Japanese) have employed non-contact forced vibrations of free-free (i.e., freely supported) beams (e.g. Fukada 1950; Obataya et al. 2000). Comparison of results on well-known or "reference" species across several sources supports the reproducibility potential of this method (e.g. analyses of the database described in Brémaud et al. 2009; Brémaud 2012).

The general objective of this work is to increase knowledge on the diversity of wood dynamic mechanical/ viscoelastic vibrational properties. In a previous article, physico-chemical indicators were proposed for estimating variations in damping coefficient (Brémaud et al. 2010b). The present paper aims at producing new and reliable data on lesser known species and at categorising sources of variations. An attempt is also made at confronting species diversity and within-species variability. Ninety-eight contrasting wood types, of which 65 had never been tested previously, are characterised. Potential sources of experimental errors are briefly reviewed, and a device and protocol are described for conducting systematic and rapid "routine" tests. Results are analysed at the specimen, wood type and species level. Repartition of properties between wood types is discussed in connection to their origin and to actual or potential acoustical end-uses.

\section{Materials and methods}

\subsection{Wood material}

Material was chosen in order to cover: (1) a wide range in botanical origins, specific gravity and extractives content; (2) both "reference" species for which data are available and species for which vibrational properties had never been studied; and (3) a range of actual or potential acoustical enduses. Seventy-nine species were studied in total. In order to confront species diversity and within-species variability, 
different wood types (WT) were collected for some species (e. g. heartwood versus sapwood or reaction versus normal wood). The sampling covered 98 WT: 19 (from 12 species) for softwoods, 14 (12 spp.) for temperate-zone hardwoods and 65 (55 spp.) for tropical hardwoods. It comprised of 264 stocks of wood, e.g. different trees and/or different "qualities". Part of the wood material was obtained from the wellidentified stocks from the CIRAD wood workshop. Another part was provided by several French instrument makers, and, when needed, botanical species were subsequently identified.

\subsection{Sampling, scaling and preparation of test specimens}

Specimens were cut to dimensions of $150 \times 12 \times 2 \mathrm{~mm}^{3}$ (longitudinal $\times$ radial $\times$ tangential), using a circular saw with a quality finishing blade and a specific machining guide and fixture. This procedure ensured smooth surfaces that did not require further processing (such as hand sanding, which would be detrimental to the parallelism of the specimen). Thickness variations were $\leq 0.05 \mathrm{~mm}$. The total number of specimens was 1,792 .

The quality of the specimens' machining is of utmost importance. The accuracy of the thickness is the main source of experimental uncertainty on the specific modulus of elasticity $\left(E^{\prime} / \gamma\right)$. Damage in the surface layers, such as those resulting from machine planing, belt sanding or milling, must be avoided, as they reduce the modulus of elasticity and increase the damping (Sali and Kopac 1998).

The sampling and scaling of specimens was carefully planned regarding local variations in wood. The width of specimens included at least one full growth ring-when these were distinct. Systematic grain angle deviations often cannot be avoided, especially so in tropical hardwoods, but they were carefully recorded, given their important effect on vibrational properties (Brémaud et al. 2010a, 2011b).

The slenderness (length/height ratio) of specimens is very important. In bending vibration, the total deflection includes a contribution of shear properties, which increases with reducing slenderness, with increasing anisotropy and with increasing order of vibration modes and frequency (Ono and Kataoka 1979; Obataya et al. 2000). This effect can be calculated (Nakao et al. 1985; Brancheriau and Baillères 2002; Kubojima et al. 2004), taking into account the range in axial-to-shear anisotropy of vibrational properties between very different woods (Brémaud et al. 2011b). For $E^{\prime}$ not to be under-evaluated by more than $2 \%$ (by Euler-Bernouilli Eq. 1, at the first bending mode), the minimum $l / h$ ratio is of the order of 25-40 for woods within the low to high range of anisotropy respectively. For $\tan \delta$ (at the first bending mode), the contribution of shear remains under $2 \%$ for $l /$ $h$ ratios $>20$ and can be neglected for $l / h$ ratios $>35$. With the usual geometry $(l / h=75)$ of specimens under study, the contribution of shear should be negligible at the first bending mode, whatever the wood type. Slenderness should also be designed so that specimen stiffness is not excessive to allow precise displacement measurements.

\subsection{Physical conditions}

Before being tested, all specimens were conditioned for at least 3 weeks in standard "air-dry" regulated conditions $\left(20 \pm 1^{\circ} \mathrm{C}\right.$ and $60-65 \%$ relative humidity $\mathrm{RH}$ ). Equilibrium moisture content (EMC, calculated from measured "air-dry" weight and after oven-drying) ranged between $6 \%$ and $12 \%$ depending on species. Differences in EMC were primarily related to those in extractives content (Brémaud et al. 2010b). According to Obataya et al. (1998), a variation in EMC from 6\% to $12 \%$ in a given wood (spruce) conditioned at different $\mathrm{RH}$ would result in a decrease in $E^{\prime} / \gamma$ of approximately $-6 \%$ and an increase in $\tan \delta$ of approximately $24 \%$. However, woods with various chemical contents can exhibit different moisture content dependence of vibrational properties (Obataya and Norimoto 1995; Obataya et al. 2001).

For practical reasons, part of the tests could not be run in the climate chamber but with an uncontrolled $\mathrm{RH}$ of 55$65 \%$. Variations in $\mathrm{MC}$ during the time of the tests were, however, quite small ( $\leq 3 \%$ relative variation, corresponding to $\leq 0.3 \%$ absolute change) and we could not detect significant short-term ( $\sim 30 \mathrm{~min})$ variation in $E^{\prime} / \gamma$ nor in $\tan \delta$. A sub-sample of 55 specimens, covering a wide range of properties, was tested in both conditions (inside and outside a climatic room) and measured values were identical on average. This, however, should not hold true if bigger differences in $\mathrm{RH}$ were considered.

\subsection{Non-contact forced-released flexural vibrations of free-free beams}

\subsubsection{Basic principle}

Slender wooden beams are hung by thin threads located at the nodes of vibration of the mode under study (here, the first mode). The specimen is made to vibrate through an electromagnet facing a thin steel piece glued to one end of the sample. A frequency sweep detects the resonance frequency, from which the specific dynamic modulus of elasticity is determined according to the Euler-Bernouilli equation:

$\frac{E^{\prime}}{\rho}=\frac{48 \pi^{2} l^{4}}{m_{n}^{4} h^{2}} f_{\mathrm{R} n}^{2}$

where $l$ is the length of the specimen and $h$ its thickness, $f_{\mathrm{Rn}}$ is the resonance frequency of the mode $n$ and $m_{n}$ is a constant depending on the mode order $\left(m_{1}=4.730\right)$. The specific modulus is expressed as $E^{\prime} / \rho$ in $\mathrm{MPa} \mathrm{m} \mathrm{m}^{3} \mathrm{~kg}^{-1}\left(\right.$ or $\mathrm{m}^{2} \mathrm{~s}^{-2}$ ) 
when using density ( $\rho$, i.e. specific mass in $\mathrm{kg} \mathrm{m}^{-3}$ ) or as $E^{\prime} / \gamma$ in GPa when using specific gravity ( $\gamma$, without unit).

The damping coefficient (or loss factor, $\tan \delta$ ) is determined, in the time-domain, through the logarithmic decrement $(\lambda=\pi \tan \delta$, Fig. 1b) of amplitudes, after stopping the excitation, which is fixed at $f_{\mathrm{R}}$. In the frequency domain, $\tan \delta$ is determined by a frequency scan, through the bandwidth $(\Delta f)$ at half-power (or at $-3 \mathrm{~dB}$ ) of the resonance curve (Fig. 1a), often called the quality factor $\left(Q^{-1}=\Delta f f f_{\mathrm{R}}\right)$. Both measurements should be equivalent $\left(\tan \delta \approx Q^{-1} \approx \lambda / \pi\right)$ for values $<<0.1$ (Jones 2001).

\subsubsection{Experimental devices and development of a semi-automated interface}

The first used device employed an eddy-current displacement sensor $(5 \mu \mathrm{m}$ resolution, distance of detection $2 \pm$ $0.2 \mathrm{~mm}$ ), facing a thin aluminium plate glued on one end of the specimen (Fig. 2). The frequency scan was imposed manually from a function generator. The resonance frequency $\left(f_{R}\right)$ and the decrement of amplitude after stopping the excitation were recorded with a fast Fourier transform (FFT) analyser, and the data files were later analysed in MS Excel. The logarithmic decrement ( $\lambda$, Fig. 1b) was determined by a regression on the peak amplitudes versus time. One triplicate test required $\geq 15 \mathrm{~min}$.

A more automated device was then designed in order to minimise the time required for a test and all manual steps (Brémaud 2006). Displacement was measured by a lasertriangulation sensor (Fig. 2), which simplifies positioning of specimens $(10 \mu \mathrm{m}$ resolution, distance of detection $40 \pm$ $4 \mathrm{~mm}$ ). Tests were fully computer-driven through a control/ acquisition card (National Instruments, Austin, TX, USA, NI PCI $6221, \mathrm{~A} / \mathrm{D}$ conversion 16 bits) and a program that we specifically developed in Labview ${ }^{\circledR}$, with the following steps (Fig. 3). A wide (150-750 Hz by default, adjustable) scan detected the first resonance frequency $f_{\mathrm{R}}$. Then, a narrower $\left(0.98 \times f_{\mathrm{R}}-1.02 \times f_{\mathrm{R}}\right.$ by default, adjustable $)$ frequency sweep was run for measuring precisely $( \pm 0.05 \mathrm{~Hz})$ $f_{\mathrm{R}}$ and the bandwidth at half-power $(\Delta f)$. The sampling rate was of $100 \mathrm{kS} / \mathrm{s}$, and the acquisition time, by default, was $10 \mathrm{~s}$. The signal (convoluted by a sine cardinal function as a "natural" window is used in order not to modify the bandwidth) was smoothed by a moving average (on 5 points), on which $f_{\mathrm{R}}$ and $\Delta f$ were determined. Vibration was then set at $f_{\mathrm{R}}$ until the vibration was stable and stopped. The logarithmic decrement $(\lambda)$ after stopping the excitation was calculated by a regression on the peak amplitudes versus time on the steadiest part of the decay. The time required for measuring $f_{\mathrm{R}}, \tan \delta=Q^{-1}$ and $\tan \delta=\lambda / \pi$ of a specimen, with three repetitions, was $\leq 5 \mathrm{~min}$.

\subsection{Validation of the experimental method}

\subsubsection{Calculated uncertainty and observed repeatability}

The theoretical uncertainty on $E^{\prime} / \gamma$ is $5.9 \%$ (due to machining precision on thickness), and variations between repetitions were $<1 \%$.

For the determination of damping by bandwidth $\left(Q^{-1}\right)$, the calculated uncertainty is governed by the frequency resolution, that is, by the sampling rate and duration of acquisition. Uncertainty will be between $2.5 \%$ and $5 \%$ at $100 \mathrm{kS} / \mathrm{s}$ over $10 \mathrm{~s}$ (or twice higher values if using a sampling rate of $50 \mathrm{kS} / \mathrm{s}$ ), for realistic ranges of $Q^{-1}$ values for wood. For $\tan \delta$ determined by logarithmic decrement, the theoretical uncertainty depends on the initial amplitude of vibration and on the spatial resolution of the displacement sensor. In our experimental conditions, it ranges from $1 \%$ to $15 \%$ (resolutions of 5 and $10 \mu \mathrm{m}$ ). Measurements by bandwidth $\left(\tan \delta=Q^{-1}\right)$ have a lower relative uncertainty for woods with higher $\tan \delta$, whereas those by logarithmic decrement $(\tan \delta=\lambda / \pi)$ have a lower relative uncertainty for woods with lower $\tan \delta$.

These calculated errors were closely matched by observed variations between repetitions (Fig. 4). Average experimental error was $3 \%$ for the bandwidth method and $5 \%$ (sensor resolution of $10 \mu \mathrm{m})$ or $2 \%(5 \mu \mathrm{m})$ by the logarithmic decrement method. For the latter, however, outof-range values were observed for specimens with excessive stiffness and/or irregular surfaces. Nevertheless, the precision of $\tan \delta$ determination in the temporal domain could be greatly improved using a simple "inverse" method (Fig. 1c). In this case, $\tan \delta$ was identified over the whole
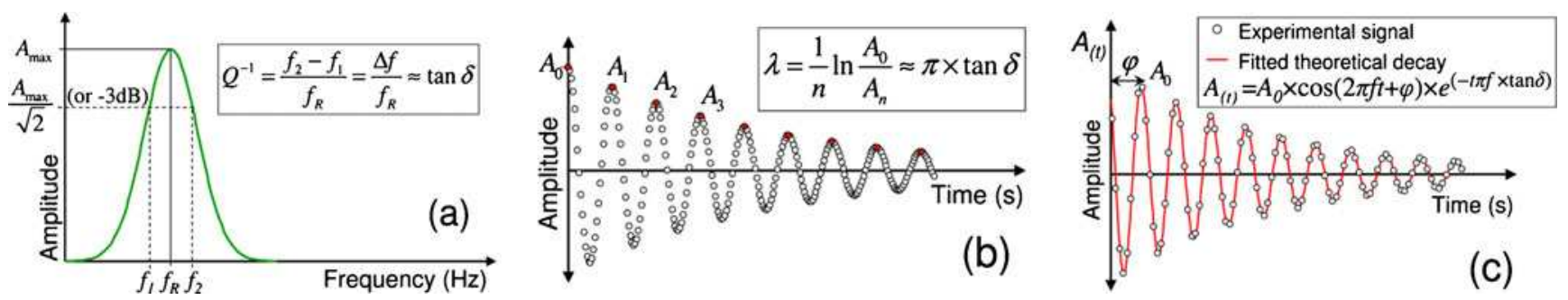

Fig. 1 Determination of $\tan \delta$ in the frequency (a) or temporal $(\mathbf{b}, \mathbf{c})$ domains. a Bandwidth method; b logarithmic decrement method; $\mathbf{c}$ "inverse" method 

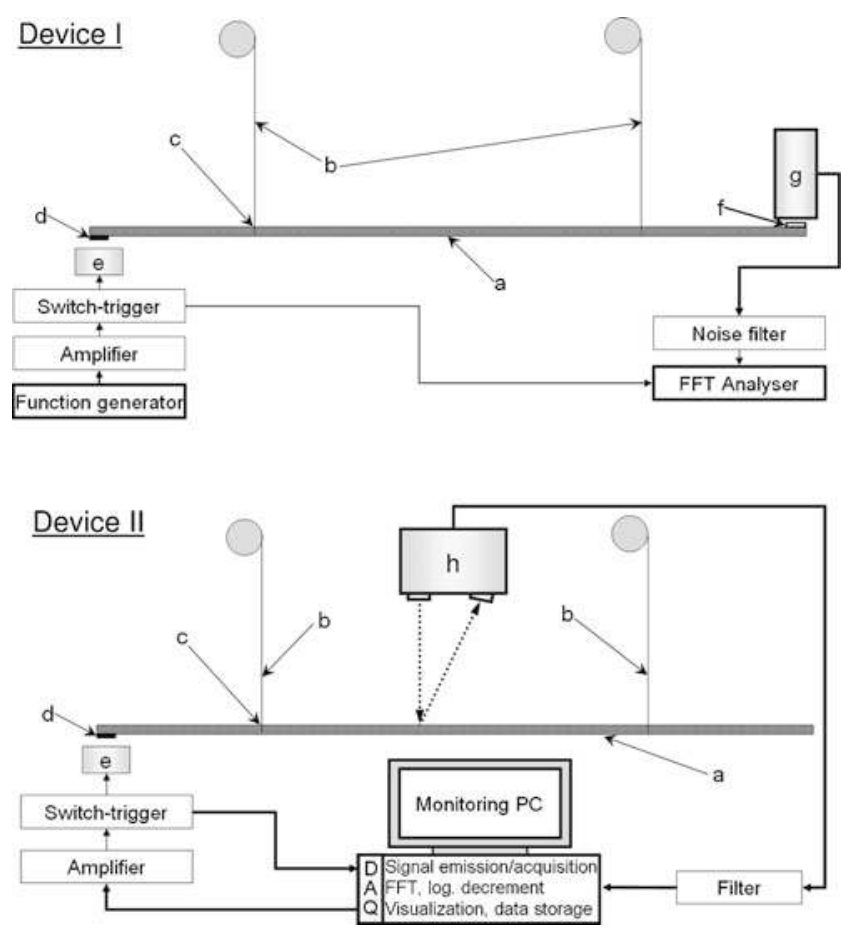

Fig. 2 Experimental devices: a wooden specimen; b supporting silk threads; c vibration node location; $\mathbf{d}$ thin steel plate; e electro-magnet. Device I: $\mathbf{g}$ eddy-current sensor facing a thin aluminium plate (f). Device II: $\mathbf{h}$ laser sensor

signal (not only peak amplitudes) by fitting the parameters of the equation of decay (Fig. 1c) to the experimental signal by optimisation (using the solver in MS Excel) so as to minimise the difference between the calculation and observations. Error was then normally $\leq 2 \%$ and did not exceed 5\% even for "odd" specimens (Fig. 4).

Globally, the experimental error on $\tan \delta$ ranged from $0 \%$ to $15.2 \%$ (mean $=3.2 \%$ ) and was $\leq 5 \%$ for $80 \%$ of all tested specimens.

\subsubsection{Comparison of measurements obtained by different methods}

The values of $\tan \delta$ determined in both the temporal and frequency domains (with the developed semi-automated device) were very consistent (Fig. 5). This is in agreement with the theory of viscoelastic damping (Jones 2001) and confirms its validity over the expectable range of axial $\tan \delta$ for "air-dry" wood. Measurements by bandwidth were on average slightly higher $(\approx+0.4 \%)$ due to the modulation of the resonance peak by the observation window.

In bending vibration tests, the specific dynamic modulus of elasticity can be derived according to either EulerBernouilli (in which the influence of shear is neglected) or to the Timoshenko theory (which takes into account the influence of shear) (e.g. Brancheriau and Baillères 2002). In order to compare the respective values obtained for $E^{\prime} / \gamma$, tests were conducted with a natural vibration method, which allows both calculations (without inputting hypothetical values for shear; Bordonné 1989). A reduced sampling of 130 beams, with dimensions $360 \times 20 \times$ $20 \mathrm{~mm}^{3}(L \times R \times T)$, were put into bending vibrations by percussion and their response (resonance frequencies of the three first bending modes) was recorded with a microphone. Beams were then cut into small specimens (2-6 per bar), which were tested by the forced vibration method.

For the same "bulk" specimens $(20 \times 20 \mathrm{~mm}$ section, $l / h$ ratio of 18$), E^{\prime} / \gamma$ calculated according to Bernouilli was on average $6 \%$ lower than according to Timoshenko (Fig. 6). For specimens tested by forced vibrations, $E^{\prime} / \gamma$ was equivalent according to both theories, as was expected given their high slenderness $(l / h=75)$ (Nakao et al. 1985; Kubojima et al. 2004). These, however, displayed more variability $\left(R^{2}=95 \%\right.$ versus $99 \%$ ) due to local variations.

\subsubsection{Additional parameters to consider}

The added mass of the thin steel piece fixed to the wooden test specimen has a negligible effect on $\tan \delta$, but decreases the

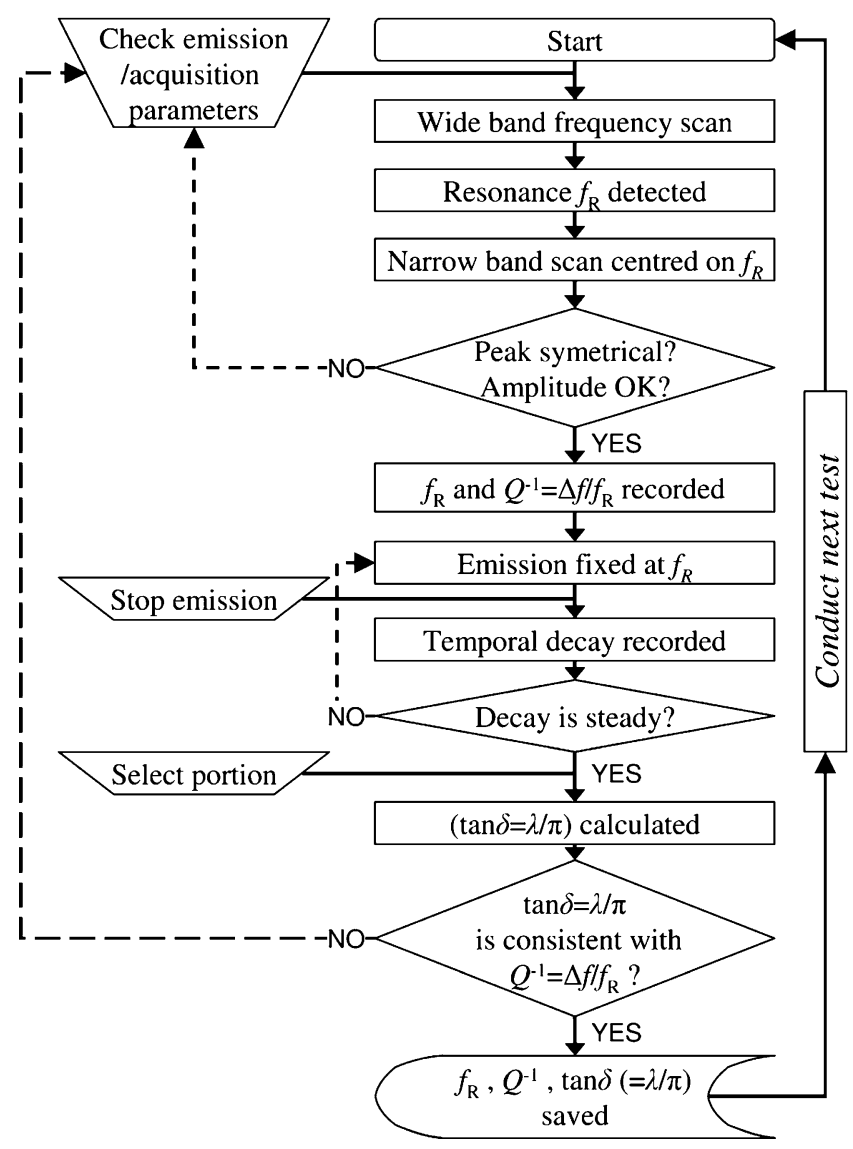

Fig. 3 Flowchart of the computer-driven vibration method developed (device II) 


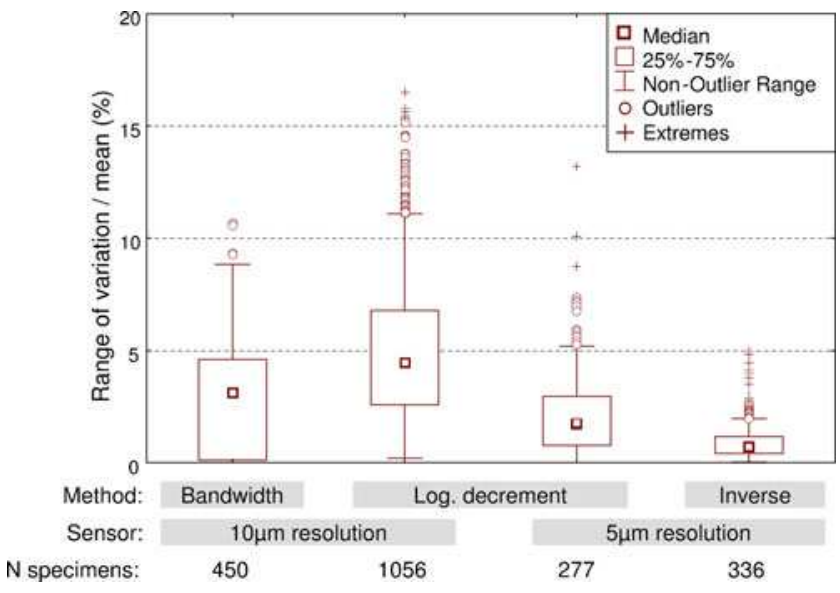

Fig. 4 Range of variation ([max $-\min ] /$ mean values) of $\tan \delta$ between 3 to 6 repetitions per specimen, with different sensors and methods of determination

resonance frequency (Kataoka and Ono 1975). Kubojima et al. (2005) calculated the change in the constant $m_{n}$ in the Euler-Bernouilli equation (Eq. 1) due to the ratio $(\mu=M / m)$ of the added mass $(M)$ to the mass of the wooden beam $(m)$. For values of $\mu \leq 5 \%$ (approximately $0.7 \%$ in our experiments), this can be approached by linear relations. The resulting decrease in apparent $E^{\prime} / \gamma$ is of $\approx-3.437 \times \mu$ and was around $-2.4 \%$ on average over all tested specimens. This effect could be neglected for dense woods, but it has to be corrected for very light ones, and subsequently must be taken into account when comparing in very different wood materials.

Supporting threads, when they are loose and flexible, have almost no influence on $f_{\mathrm{R}}$ (Brancheriau and Baillères 2002) or on $\tan \delta$ measurements, even if they are not strictly located at the position of the first mode's node: An inaccuracy of $\pm 5 \%$ of the total length should remain acceptable (Kataoka and Ono 1975). Tight or stiff supporting threads, however, may interfere with the specimen vibration and/or result in a coupling with the device's frame

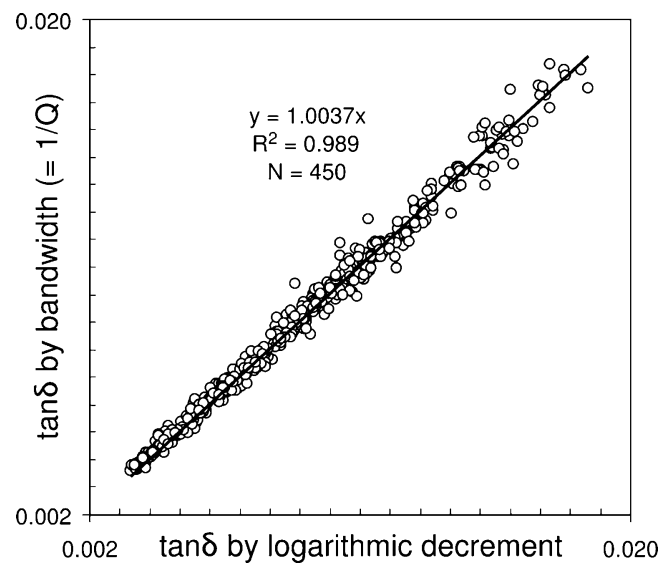

Fig. 5 Comparison of $\tan \delta$ determined in the temporal (logarithmic decrement method) and frequency (bandwidth method) domains. Each point: average of three repetitions

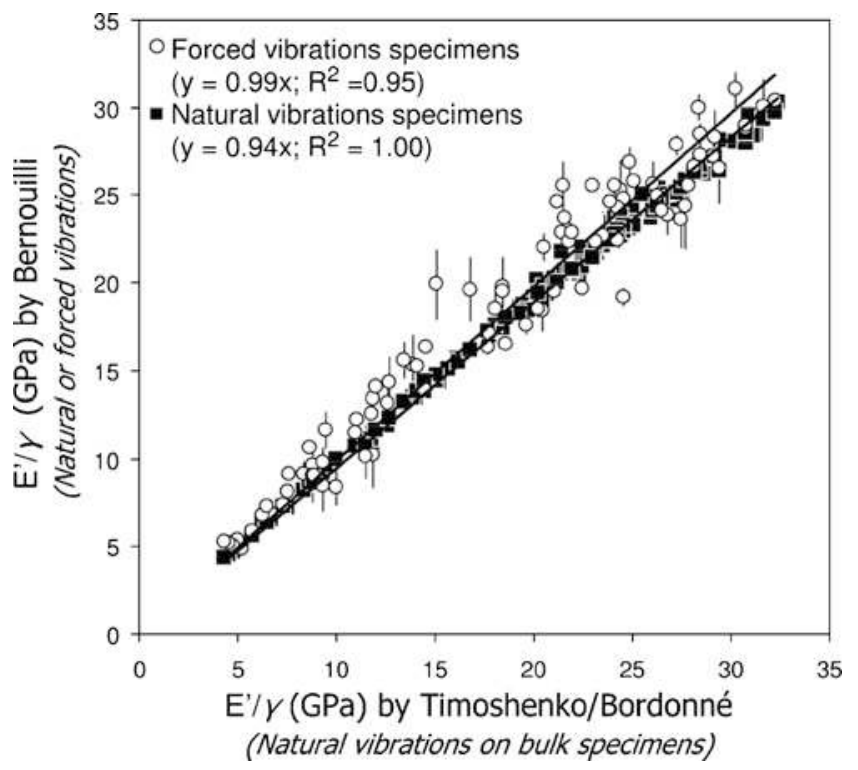

Fig. 6 Comparison of $E^{\prime} / \gamma$ calculated according to Euler-Bernouilli (for small slender specimens in forced vibrations and bulk specimens in natural vibration) and to Timoshenko (for bulk specimens in natural vibration). Vertical error bars: standard deviation between 2 and 6 small specimens prepared from a bulk one

(Brancheriau et al. 2010). Tan $\delta$ and $f_{\mathrm{R}}$ are stable when the distance between the exciting electro-magnet and the steel piece is $\geq 2 \mathrm{~mm}$, but measurements are affected when this distance is $<1 \mathrm{~mm}$ (Kataoka and Ono 1975).

The fluid friction with air does not affect damping under the usual test conditions (Kataoka and Ono 1975; David 1999). In the low-frequency range $(<100 \mathrm{~Hz})$, however, its contribution would not be negligible for thin wooden beams (Kitahara and Matsumoto 1973).

\subsection{Data sorting and statistical analysis}

Data were analysed at the specimen, wood type, and species levels. First, all tested specimens $(N=1,792)$ were used for analysing the relationship between $\tan \delta$ and $E^{\prime} / \gamma$, by comparing present results with the "standard" trend from Ono and Norimoto $(1983,1984)$ :

$\tan \delta_{\mathrm{S}}=10^{-A} \times\left(E^{\prime} / \rho\right)^{-B}$

where $\tan \delta_{\mathrm{S}}$ is "standard" damping coefficient and coefficients $A$ and $B$ are 1.23 and 0.68 over a wide range of softwoods (further detailed below in Sections 3 and 4).

Then, analyses of this relationship were detailed for three broad groups of normal wood: softwoods and hardwoods with low or high extractives content (EC). Classification into low $(<5 \%)$ or high $(>7 \%)$ EC was based on available database (e.g. Brémaud et al. 2010b) and/or literature values. Sapwood was usually considered as low EC unless contradictory data were known. Species with medium 
(5-7\%) EC and species for which no information on EC could be obtained were excluded from this analysis, as were some samples with atypical heartwood. Specimens with important grain deviations were included in analyses of the $\tan \delta-E^{\prime} / \gamma$ relationship. However, these specimens were excluded from basic statistics on the different wood types, for which 1,317 specimens were kept as representative (see Table 1). Data were first averaged between different specimens from a given stock, then between the means of different stocks (when applicable).

The "deviation from standard damping" $=\mathrm{DS} \delta$ (Brémaud 2006; Brémaud et al. 2009, 2010b) was used for expressing the "intrinsic viscosity" (i.e. de-correlated from specific modulus of elasticity) of the different wood types:

$D S \delta=100 \times \frac{\tan \delta_{\mathrm{i}}-\tan \delta_{\mathrm{S}}}{\tan \delta_{\mathrm{S}}}$

where $\tan \delta_{i}$ is the damping coefficient of a given wood, and $\tan \delta_{S}$ is the standard damping from Eq. 2 .

In order to compare all wood types according to various properties, principal component analysis (PCA) was performed, using XLstat ${ }^{\circledR}$ (Addinsoft SARL) in MS Excel. Active variables represented the three main aspects of specific gravity, elasticity and viscosity and were selected to be as far as possible de-correlated from each other. That is, "elasticity" was represented by $E^{\prime} / \gamma$ (instead of Young's modulus $E^{\prime}$, which is quite strongly correlated to specific gravity) and "viscosity" by DS $\delta$ (Eq. 3 above). The broad categories "softwoods", "temperate hardwoods" and "tropical hardwoods" were added as inactive qualitative variables.

\section{Results}

\subsection{Total diversity at the specimens' level}

Over all individual specimens, measured properties covered a continuous and broad range: $0.21-1.38$ for specific gravity, 4.6-34.1 GPa for $E^{\prime} / \gamma, 3.3 \times 10^{-3}$ to $20.6 \times 10^{-3}$ for $\tan \delta$ (Table 1). Damping coefficient had the highest coefficient of variation $(>40 \%)$, but the three properties covered a similar span (ratio between maximum and minimum values of 6-7).

Damping coefficient and specific modulus of elasticity followed a relationship very similar to the "standard" one (Eq. 2). This "standard" relationship was reported by Ono and Norimoto $(1983,1984)$ in the logarithmic representation shown in Fig. 7, by plotting $\tan \delta /\left(E^{\prime} / \gamma\right.$ ) (which is supposed to be proportional to the energy dissipated per vibration cycle) versus $E^{\prime} / \gamma$. This representation, however, reduces the apparent dispersion. When plotting directly $\tan \delta$ versus $E^{\prime} / \gamma$ (as in Fig. 8), the relationship has the form of a power law: $\tan \delta=10^{-A} \times\left(E^{\prime} / \gamma\right)^{-B}$ (i.e. linear regressions can be performed in a log-log scale, shown in the inset of Fig. 8). On all studied specimens of very different wood types, the relationship was highly significant (at a level< $0.1 \%$ : Pearson's coefficient of correlation $R=0.71, N=1,792$ ), but explained only half of the variations in $\tan \delta\left(R^{2}=0.5\right)$. This strength of association is of the same order as above references, when comparing the coefficients of determination $\left(R^{2}\right)$ obtained in the two different representations [i.e. by plotting $\tan \delta$ directly, or $\tan \delta /\left(E^{\prime} / \gamma\right)$, versus $E^{\prime} / \gamma$ ] (Table 2). Distinct categories - softwoods, hardwoods with low or high extractives content-showed lower dispersion $\left(R^{2}=0.76\right.$, 0.73 and 0.57 , respectively) and nearly parallel trends, but shifted towards higher or lower tan $\delta$ values (Fig. 8).

\subsection{Species diversity in vibrational properties}

Considering the mean properties of normal heartwood from the different species (Table 3), the specific gravity $(\gamma)$ ranged from 0.22 (Ceiba pentandra) to 1.31 (snakewood= Brosimum guianense); the specific storage modulus $\left(E^{\prime} / \gamma\right)$ from 9.0 $\mathrm{GPa}$ (Pinus caribeae) to $32.2 \mathrm{GPa}$ (Picea sitchensis); and the damping coefficient $(\tan \delta)$ from $3.9 \times$ $10^{-3}$ (Aniba canellila) to $18.7 \times 10^{-3}$ (Arbutus unedo). However, the widest range in $E^{\prime} / \gamma$ was observed when including reaction woods: from $6.3 \mathrm{GPa}$ (compression

Table 1 Basic statistics of total diversity in specific gravity $(\gamma)$, specific modulus of elasticity $\left(E^{\prime} / \gamma\right)$ and damping coefficient (tan $\left.\delta\right)$, between specimens and between wood types

\begin{tabular}{|c|c|c|c|c|c|c|c|c|c|c|}
\hline & \multirow[t]{2}{*}{$N$} & \multicolumn{3}{|l|}{$\gamma$} & \multicolumn{3}{|c|}{$E^{\prime} / \gamma(\mathrm{GPa})$} & \multicolumn{3}{|c|}{$\tan \delta\left(10^{-3}\right)$} \\
\hline & & Range & Mean & $\mathrm{CV}(\%)$ & Range & Mean & CV $(\%)$ & Range & Mean & CV $(\%)$ \\
\hline \multicolumn{11}{|l|}{ Specimen level } \\
\hline All specimens & 1,792 & $0.21-1.38$ & 0.84 & 26 & $4.6-34.1$ & 18.5 & 33 & $3.3-20.6$ & 7.1 & 41 \\
\hline Representative of wood types & 1,317 & $0.21-1.38$ & 0.86 & 28 & $4.6-34.1$ & 19.7 & 30 & $3.3-20.6$ & 6.9 & 44 \\
\hline \multicolumn{11}{|l|}{ Wood type level } \\
\hline All wood types & 98 & $0.22-1.31$ & 0.81 & 31 & $6.3-32.7$ & 20.0 & 32 & $3.9-18.7$ & 7.7 & 42 \\
\hline Normal heartwood & 78 & $0.22-1.31$ & 0.83 & 30 & $9.0-32.2$ & 20.0 & 29 & $3.9-18.7$ & 7.4 & 43 \\
\hline
\end{tabular}




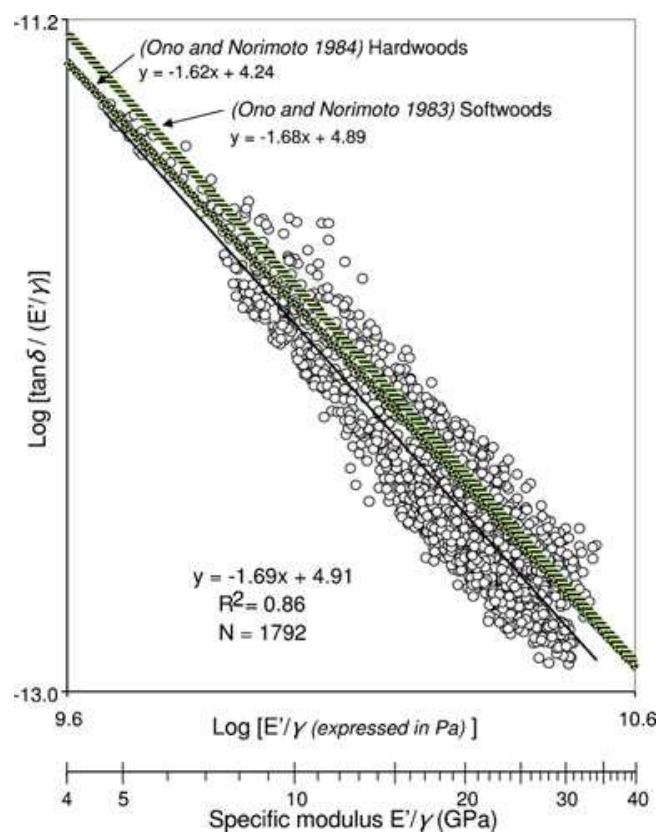

Fig. 7 Relationship between damping coefficient and specific dynamic modulus of elasticity: comparison of our global sampling with trends reported by Ono and Norimoto $(1983,1984)$ by plotting $\tan \delta /\left(E^{\prime} / \gamma\right)$ versus $E^{\prime} / \gamma$ on $\log -\log$ scale

wood of Pinus pinaster) to $32.7 \mathrm{GPa}$ (tension wood from Populus sp.). The span in properties (ratio of maximum to minimum values) was 6.0 for $\gamma, 4.8$ for $\tan \delta$ and 3.6 for $E^{\prime \prime}$ $\gamma$ (5.2 when including reaction wood). As previously observed at the specimen level, $\tan \delta$ had the highest coefficient of variation between species (normal heartwood)

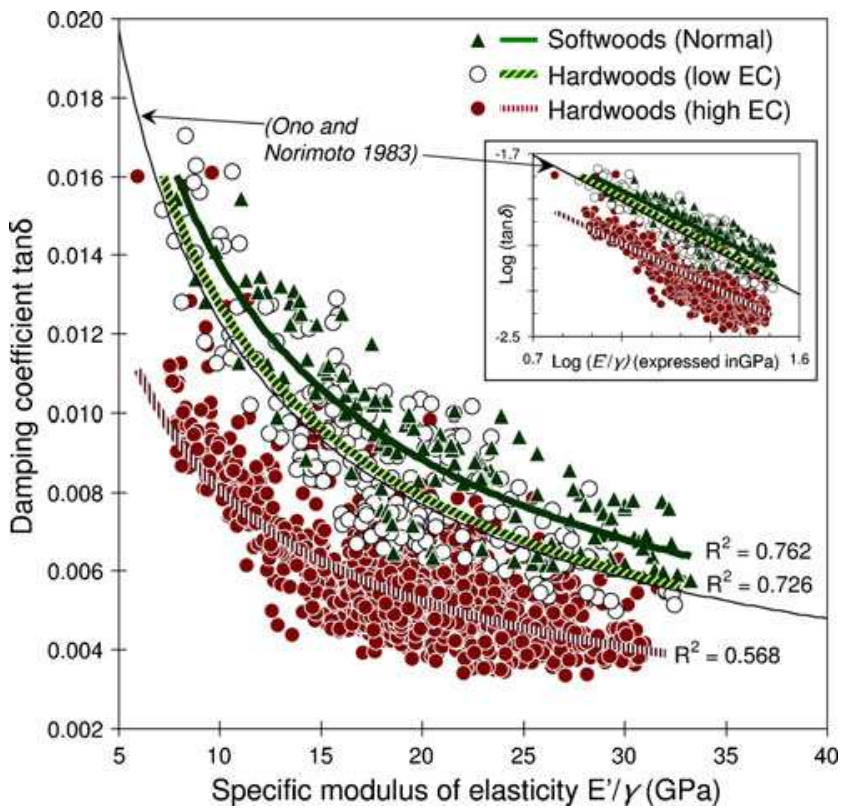

Fig. 8 Relationships between $\tan \delta$ and $E^{\prime} / \gamma$ for normal wood of softwoods and of hardwoods with low $(<5 \%)$ or high $(>7 \%)$ extractives content. The inset shows the logarithmic representation, which allows calculation of linear regressions and between all wood types (Fig. 9; Table 1). On the contrary, within a given wood type, $\tan \delta$ was a little less variable than $E^{\prime} / \gamma$ (mean coefficient of variation of $9 \%$ and $11 \%$, respectively).

\subsection{Principal components analysis on wood types}

Principal components analysis allows representation of the diversity of wood types according to several properties. As active variables should be as independent as possible, the analysis was conducted on $\gamma, E^{\prime} / \gamma$, and the deviation of damping from the standard $\tan \delta-E^{\prime} / \gamma$ trend (DS $\delta$, Eq. 3). The Young's modulus $\left(E^{\prime}\right)$, specific loss modulus $\left(E^{\prime \prime} / \gamma=\tan \delta \times E^{\prime} / \gamma\right)$ and damping coefficient $(\tan \delta)$ were projected as inactive variables (Fig. 10a) in order to better understand the repartition of the individuals. Schematically, axis 1 mainly denotes "solidity" (high $\gamma$ and $E^{\prime}$, reflecting porosity of the cellular material), vertical axis 2 is principally governed by $E^{\prime} / \gamma$ (related to microfibril and/or grain angle), and the upper-left to lower-right diagonal expresses a decreasing viscous behaviour (DS $\delta$ and $E^{\prime \prime} / \gamma$ ), which is mostly related to chemical composition (Brémaud et al. 2010b, 2011c).

\section{Discussion}

4.1 Interpretation of the $\tan \delta-E^{\prime} / \gamma$ relationship in terms of sources of variability between wood types

For hardwood specimens with low extractives content (EC), the relationship between $\tan \delta$ and $E^{\prime} / \gamma$ had a $R^{2}$ of $73 \%$ and constants $A$ and $B$ (Table 2) nearly equal to the values of the "standard" relationship on softwoods (Ono and Norimoto 1983). The results in Ono and Norimoto (1983) are based on 25 species, which represent quite well different gymnosperm families, whereas the present study had only 12 softwood species, which were mostly Pinaceae for which damping is usually higher than average (Brémaud et al. 2009). Accordingly, the "softwood" trend here had slightly higher $\tan \delta$ values than the "standard", but was also slightly less dispersed (Table 2). Conversely, the hardwood relationship from Ono and Norimoto (1984) is much more dispersed (Table 2 ) and has slightly lower $(\approx-6 \%) \tan \delta$ than the "softwood standard", probably because it includes several tropical species with high extractives content. The trend observed here on hardwood specimens with high EC (>7\%) shows they clearly had a lower $\tan \delta(-33 \%$ in average) at a given $E^{\prime} / \gamma$, and a higher dispersion $\left(R^{2}=57 \%\right)$, than both "standard softwoods" and hardwoods with low EC.

The relationship between $\tan \delta$ and $E^{\prime} / \gamma$ is governed by the orientation of wood elements and can be reconstructed by models taking into account either the microfibril angle 
Table 2 Parameters of the relationship $\tan \delta=10^{-A} \times\left(E^{\prime} / \gamma\right)^{-B}$ as obtained by regressions on different samples

\begin{tabular}{lccccc}
\hline & $N$ specimens & $A$ & $B$ & $\begin{array}{l}\mathrm{R}_{\text {direct }}^{2} \\
\tan \delta=f\left(E^{\prime} / \gamma\right)\end{array}$ & $\begin{array}{c}R_{\text {combined }}^{2} \\
\tan \delta /\left(E^{\prime} / \gamma\right)=f\left(E^{\prime} / \gamma\right)\end{array}$ \\
\hline All samples & 1,792 & 1.322 & 0.692 & 0.50 & 0.86 \\
Softwoods (normal wood=NW) & 140 & 1.222 & 0.639 & 0.76 & 0.95 \\
Hardwoods (NW) with high extractives content & 1,153 & 1.474 & 0.620 & 0.57 & 0.90 \\
Hardwoods (NW) with low extractives content $^{25}$ softwood species $^{\mathrm{a}}$ & 221 & 1.231 & 0.677 & 0.73 & 0.94 \\
30 hardwood species $^{\mathrm{b}}$ & 1,227 & 1.23 & 0.68 & & 0.91 \\
\end{tabular}

Constants are derived from regressions based on $E^{\prime} / \gamma$ expressed in GPa. $R_{\text {direct }}^{2}$ and $R_{\text {combined }}^{2}=$ coefficient of determination obtained from plotting $\tan \delta$ directly versus $E^{\prime} / \gamma$, or $\tan \delta /\left(E^{\prime} / \gamma\right)$ versus $E^{\prime} / \gamma$, respectively

${ }^{a}$ Ono and Norimoto (1983)

(Obataya et al. 2000) or the grain angle (Brémaud et al. 2011b). Vertical shifts of curves can reflect differences in chemical composition (Obataya et al. 2000; Brémaud et al. 2010a, 2011a,c) and/or in wood moisture content (Obataya et al. 1998; Sasaki et al. 1988), both of which affect $\tan \delta$ more than $E^{\prime} / \gamma$. A shift in $\tan \delta$ of approximately $30 \%$ was observed between the trend for normal wood and that for compression wood (species: spruce and pines) due to variations in lignin composition and structure (Brémaud et al. 2011c). Extractives, on the other hand, can either be neutral or decrease (or sometimes increase) $\tan \delta$ by as much as a factor 2, while affecting only marginally the axial $E^{\prime} / \gamma$ (Brémaud et al. 2010a,b, 2011a; Matsunaga et al. 1996; Minato et al. 1997, 2010; Obataya et al. 1999; Sakai et al. 1999; Yano 1994; Yano et al. 1995). This appears consistent with the important shift between the trends for hardwoods with low and high EC and with the high dispersion for the later. Extractives can also modify wood equilibrium moisture content (e.g. Hernandez 2007) in a range of about $6-12 \%$ $\mathrm{EMC}$ at $20^{\circ} \mathrm{C}$ and $65 \% \mathrm{RH}$ (Brémaud et al. 2010b), but moisture-related shifts in the $\tan \delta-E^{\prime} / \gamma$ trends mostly take place at higher wood MC (Sasaki et al. 1988).

Thus, the "standard" relationship from Ono and Norimoto (1983) was confirmed by present results, both qualitatively (general form) and quantitatively (values of the constants $A$ and $B$ in Eq. 2, Table 2), and concerns, statistically, both representative softwoods and hardwoods with low extractive content. Deviations of damping coefficient of a given wood from this standard trend can be considered as a "normalised damping" $(D S \delta$, Eq. 3), relatively de-correlated from the effect of orientation, and mostly related to chemical variations.

\subsection{Distribution of vibrational properties between broad categories}

Globally, wood types were rather broadly distributed along the range of $\gamma$ and $E^{\prime} / \gamma$ (Fig. 9a, d). Tropical hardwoods covered the whole range of specific gravity but with a predominance of high values. Some of the studied softwoods and temperate hardwoods, however, were also denser than usual (normal wood of yew and compression woods of spruce and pines, secondary species of hardwoods with $\gamma \geq 0.9$ ). Softwoods (which included both compression wood, and the so-called "resonance wood" selected for string instruments soundboards) had the most scattered values of $E^{\prime} / \gamma$. Tempered and tropical hardwoods were more distributed towards, respectively, lower and higher ranges of $E^{\prime} / \gamma$. Consequently, together with their often high $\gamma$, Young's modulus ( $E^{\prime}$, Fig. 9b) higher than $20 \mathrm{GPa}$ could only be found for tropical hardwoods. These were also the only category with very low $\left(<6 \times 10^{-3}\right) \tan \delta$ (Fig. 9e). This confirms that tropical hardwoods could not be replaced by temperate-zone species for applications requiring very low damping (e.g. xylophones) and/or high Young's modulus (e.g. violin bows) (Holz 1996; Brémaud and Poidevin 2009; Brémaud 2012; Bucur 2006; Wegst 2006). The predominance of low $\tan \delta$ for tropical hardwoods partly results from their often high values of $E^{\prime} / \gamma$ (as both properties are still correlated at the wood type level) and also from a lower intrinsic damping (DS $\delta$, Fig. 9f), which is mostly due to their often higher content of "mechanically active" extractive components (Brémaud et al. 2010b).

4.3 Classification of wood types in relation to their origins and potential uses

In the PCA on all wood types, globally, a "continuum" of behaviour was observed, although the different wood categories cover preferential areas (Fig. 10b). The right-hand part of the "individuals" graph was characteristic of tropical hardwoods, in which some sub-groups may be defined. From a botanical point of view, the lower right corner (i.e. exceptionally low loss parameters and moderate $E^{\prime} / \gamma$ ) was dominated by heartwood of species from certain genera (Dalbergia, Pterocarpus and Platymiscium) belonging to the Dalbergieae tribe (=dalbergioid clade, Leguminosae- 
Table 3 Mean $(m)$ values and coefficient of variation $\left(\mathrm{CV}=\right.$ standard deviation/mean) of specific gravity $(\gamma)$, specific storage modulus $\left(E^{\prime} / \gamma\right)$ and damping coefficient $(\tan \delta)$ for normal heartwood of all studied species

\begin{tabular}{|c|c|c|c|c|c|c|c|c|c|c|c|}
\hline \multirow[t]{2}{*}{ Family } & \multirow[t]{2}{*}{ Category } & \multirow[t]{2}{*}{ Species } & \multirow[t]{2}{*}{ Code } & \multirow[t]{2}{*}{$N$ specimens } & \multirow[t]{2}{*}{$N$ stocks } & \multicolumn{2}{|l|}{$\gamma$} & \multicolumn{2}{|c|}{$E^{\prime} / \gamma(\mathrm{GPa})$} & \multicolumn{2}{|c|}{$\tan \delta\left(10^{-3}\right)$} \\
\hline & & & & & & $m$ & $\begin{array}{l}\mathrm{CV} \\
(\%)\end{array}$ & $m$ & $\begin{array}{l}\mathrm{CV} \\
(\%)\end{array}$ & $m$ & $\begin{array}{l}\mathrm{CV} \\
(\%)\end{array}$ \\
\hline PINA & $\mathrm{S}$ & Abies alba Mill. & Abi.al & 4 & 1 & 0.54 & 4 & 30.0 & 5 & 6.7 & 4 \\
\hline ACER & Te.H & Acer pseudoplatanus $\mathrm{L}$. & Ace.ps & 1 & 1 & 0.64 & & 10.6 & & 16.1 & \\
\hline ACER & Te.H & Acer sp. (American) & Ace.sp & 1 & 1 & 0.72 & & 10.5 & & 11.5 & \\
\hline CAES & Tr.H & Afzelia bipindensis Harms. & Afz.bi & 13 & 5 & 0.82 & 5 & 23.5 & 10 & 4.2 & 7 \\
\hline CAES & Tr.H & Afzelia quanzensis Welw. & Afz.qu & 5 & 1 & 0.85 & 7 & 12.7 & 5 & 11.1 & 16 \\
\hline LAUR & Tr.H & Aniba canelilla (Kunth) Mez & Ani.ca & 9 & 1 & 1.20 & 2 & 29.1 & 4 & 3.9 & 5 \\
\hline ERIC & Te.H & Arbutus unedo L. & Arb.un & 5 & 1 & 0.94 & 2 & 12.0 & 7 & 18.7 & 9 \\
\hline SAPO & Tr.H & Baillonella toxisperma Pierre & Bai.to & 6 & 1 & 0.83 & 1 & 21.2 & 3 & 7.2 & 4 \\
\hline PAPI & Tr.H & $\begin{array}{l}\text { Bobgunnia fistuloides (Harms) } \\
\text { Kirkbr. \& Wiersema }\end{array}$ & Bob.fi & 19 & 2 & 0.96 & 5 & 17.3 & 10 & 4.8 & 8 \\
\hline PAPI & Tr.H & Bocoa prouacensis Aubl. & Boc.pr & 35 & 5 & 1.26 & 2 & 26.0 & 10 & 4.2 & 12 \\
\hline MORA & Tr.H & Brosimum guianense (Aubl.) Huber & Bro.gu & 41 & 11 & 1.31 & 2 & 22.5 & 7 & 5.4 & 10 \\
\hline MORA & Tr.H & Brosimum rubescens Taub. & Bro.ru & 39 & 7 & 0.99 & 6 & 23.3 & 11 & 4.5 & 8 \\
\hline MORA & Tr.H & Brosimum utile Pitt. & Bro.ut & 5 & 1 & 0.47 & 3 & 21.7 & 8 & 8.6 & 15 \\
\hline BUXA & Te.H & Buxus sempervirens $\mathrm{L}$. & Bux.se & 6 & 2 & 0.93 & 0 & 9.6 & 12 & 15.3 & 9 \\
\hline CAES & Tr.H & Caesalpinia echinata Lam. & Cae.ec & 55 & 15 & 1.01 & 9 & 21.5 & 11 & 4.4 & 14 \\
\hline BETU & Te.H & Carpinus betulus L. & Car.be & 9 & 2 & 0.74 & 0 & 20.8 & 2 & 9.5 & 1 \\
\hline MELI & Tr.H & Cedrela odorata $\mathrm{L}$. & Ced.od & 1 & 1 & 0.48 & & 21.8 & & 7.8 & \\
\hline BOMB & Tr.H & Ceiba pentandra Gaertn. & Cei.pe & 5 & 1 & 0.22 & 10 & 10.1 & 13 & 14.0 & 12 \\
\hline CUPR & S & Chamaecyparis sp. (Hinoki) & Cha.sp & 14 & 1 & 0.39 & 3 & 27.0 & 7 & 6.3 & 6 \\
\hline LAUR & Tr.H & Chlorocardium rodiei (Schomb.) Rohwer & Chl.ro & 4 & 1 & 1.05 & 1 & 27.8 & 2 & 4.3 & 4 \\
\hline CORN & Te.H & Cornus mas L. & Cor.ma & 4 & 1 & 1.11 & 0 & 15.6 & 2 & 8.3 & 7 \\
\hline CUPR & S & Cupressus sempervirens $\mathrm{L}$. & Cup.se & 11 & 3 & 0.49 & 13 & 17.1 & 17 & 8.9 & 19 \\
\hline PAPI & Tr.H & Dalbergia baronii Baker & Dal.ba & 14 & 1 & 0.75 & 3 & 19.4 & 8 & 5.2 & 7 \\
\hline PAPI & Tr.H & Dalbergia latifolia Roxb. & Dal.la & 1 & 1 & 0.75 & & 18.5 & & 7.3 & \\
\hline PAPI & Tr.H & Dalbergia maritimensis or D. louvelli & Dal.ma & 5 & 2 & 1.07 & 10 & 21.0 & 2 & 4.0 & 17 \\
\hline PAPI & Tr.H & Dalbergia melanoxylon Guill. et Perr. & Dal.me & 10 & 2 & 1.31 & 1 & 15.7 & 12 & 5.8 & 14 \\
\hline PAPI & Tr.H & Dalbergia nigra (Vell.) Allemão ex Benth. & Dal.ni & 1 & 1 & 0.81 & & 20.5 & & 7.0 & \\
\hline PAPI & Tr.H & Dalbergia retusa Hemsley & Dal.re & 1 & 1 & 0.95 & & 11.8 & & 8.6 & \\
\hline PAPI & Tr.H & Dalbergia sp. (Bahia) & Dal.sB & 3 & 1 & 1.15 & 2 & 13.0 & 4 & 4.7 & 7 \\
\hline PAPI & Tr.H & Dalbergia sp. (Madagascar) & Dal.sM & 53 & 9 & 0.96 & 11 & 20.1 & 10 & 4.6 & 8 \\
\hline PAPI & Tr.H & Dalbergia sp. (Jacaranda do Para) & Dal.sP & 1 & 1 & 0.88 & & 18.4 & & 5.6 & \\
\hline CAES & Tr.H & Dialium cochinchinense Pierre & Dia.co & 4 & 1 & 1.10 & 2 & 24.0 & 5 & 6.4 & 13 \\
\hline CAES & Tr.H & Dialium pachyphyllum Harms & Dia.pa & 12 & 2 & 1.01 & 13 & 26.3 & 6 & 6.2 & 8 \\
\hline EBEN & Tr.H & Diospyros sp. (Madagascar) & Dio.sp & 3 & 1 & 1.18 & 0 & 16.8 & 1 & 9.1 & 5 \\
\hline PAPI & Tr.H & Dipteryx odorata (Aubl.) Willd. & Dip.od & 9 & 1 & 0.99 & 3 & 16.4 & 2 & 5.9 & 3 \\
\hline CAES & Tr.H & Guibourtia arnoldiana J.Leon. & Gui.ar & 4 & 1 & 0.84 & 1 & 25.8 & 1 & 5.6 & 4 \\
\hline CAES & Tr.H & Guibourtia conjugata (Bolle) J. Léonard & Gui.co & 2 & 1 & 1.02 & 1 & 17.0 & 1 & 7.5 & 5 \\
\hline CAES & Tr.H & Guibourtia sp. & Gui.sp & 7 & 2 & 0.89 & 8 & 16.6 & 29 & 10.7 & 8 \\
\hline CAES & Tr.H & Hymenaea courbaril L. & Hym.co & 8 & 1 & 0.77 & 4 & 28.4 & 5 & 5.3 & 2 \\
\hline CAES & Tr.H & Hymenaea parvifolia Huber & Hym.pa & 9 & 1 & 1.11 & 2 & 23.4 & 5 & 5.0 & 1 \\
\hline JUGL & Te.H & Juglans nigra $\mathrm{L}$. & Jug.ni & 1 & 1 & 0.58 & & 12.7 & & 8.0 & \\
\hline MELI & Tr.H & Khaya senegalensis (Desr.) A. Juss. & Kha.se & 4 & 1 & 0.85 & 0 & 9.2 & 4 & 12.0 & 6 \\
\hline PAPI & Te.H & Laburnum anagyroides Medik. & Lab.al & 12 & 3 & 0.90 & 6 & 13.4 & 8 & 9.2 & 6 \\
\hline LAUR & Tr.H & Licaria cannella (Meisn.) Kosterm. & Lic.ca & 16 & 7 & 1.01 & 5 & 26.1 & 9 & 5.6 & 8 \\
\hline STER & Tr.H & Mansonia altissima (A. Chev.) A. Chev & Man.al & 4 & 1 & 0.62 & 4 & 21.4 & 9 & 5.7 & 5 \\
\hline MYRI & Tr.H & Mauloutchia sp. & Mau.sp & 5 & 1 & 0.71 & 1 & 26.6 & 8 & 7.7 & 7 \\
\hline PAPI & Tr.H & Millettia laurentii De Wild. & Mil.la & 9 & 1 & 0.93 & 2 & 23.3 & 3 & 4.8 & 6 \\
\hline CLUS & Tr.H & Moronobea coccinea Aubl. & Mor.co & 8 & 1 & 0.92 & 1 & 25.1 & 2 & 4.7 & 3 \\
\hline MORA & Tr.H & Morus mesozygia Stapf. & Mor.me & 3 & 1 & 0.87 & 2 & 19.3 & 7 & 5.1 & 1 \\
\hline PAPI & Tr.H & Ormosia flava (Ducke) Rudd & Orm.fl & 9 & 1 & 0.84 & 1 & 29.9 & 4 & 4.5 & 9 \\
\hline CAES & Tr.H & Peltogyne venosa (Vahl) Benth. & Pel.ve & 8 & 2 & 0.80 & 0 & 26.8 & 7 & 5.6 & 7 \\
\hline
\end{tabular}


Table 3 (continued)

\begin{tabular}{|c|c|c|c|c|c|c|c|c|c|c|c|}
\hline \multirow[t]{2}{*}{ Family } & \multirow[t]{2}{*}{ Category } & \multirow[t]{2}{*}{ Species } & \multirow[t]{2}{*}{ Code } & \multirow[t]{2}{*}{$N$ specimens } & \multirow[t]{2}{*}{$N$ stocks } & \multicolumn{2}{|l|}{$\gamma$} & \multicolumn{2}{|c|}{$E^{\prime} / \gamma(\mathrm{GPa})$} & \multicolumn{2}{|c|}{$\tan \delta\left(10^{-3}\right)$} \\
\hline & & & & & & $m$ & $\begin{array}{l}\mathrm{CV} \\
(\%)\end{array}$ & $m$ & $\begin{array}{l}\mathrm{CV} \\
(\%)\end{array}$ & $m$ & $\begin{array}{l}\mathrm{CV} \\
(\%)\end{array}$ \\
\hline PINA & $\mathrm{S}$ & Picea abies Karst. & Pic.ab & 40 & 14 & 0.50 & 10 & 24.4 & 18 & 8.4 & 8 \\
\hline PINA & $\mathrm{S}$ & Picea sitchensis (Bong.) Carr. & Pic.si & 5 & 1 & 0.47 & 1 & 32.2 & 2 & 5.9 & 2 \\
\hline PINA & $\mathrm{S}$ & Pinus caribaea Morelet & Pin.ca & 3 & 1 & 0.36 & 4 & 9.0 & 2 & 13.2 & 3 \\
\hline PINA & $\mathrm{S}$ & Pinus nigra subsp. laricio Maire & Pin.ni & 5 & 1 & 0.51 & 4 & 19.2 & 6 & 8.8 & 6 \\
\hline PINA & $\mathrm{S}$ & Pinus patula Schiede ex. Schlecht. et Cham. & Pin.pa & 4 & 1 & 0.54 & 9 & 31.1 & 3 & 6.6 & 5 \\
\hline PINA & $\mathrm{S}$ & Pinus pinaster Aiton & Pin.pi & 18 & 7 & 0.42 & 6 & 14.2 & 12 & 12.0 & 10 \\
\hline PINA & $\mathrm{S}$ & Pinus sylvestris $\mathrm{L}$. & Pin.sy & 14 & 5 & 0.48 & 12 & 17.9 & 14 & 10.6 & 13 \\
\hline PAPI & Tr.H & Platymiscium sp. & Pla.sp & 4 & 1 & 1.02 & 1 & 25.5 & 5 & 4.8 & 2 \\
\hline PAPI & Tr.H & Platymiscium ulei Harms & Pla.ul & 19 & 3 & 0.73 & 9 & 20.4 & 7 & 4.8 & 11 \\
\hline ROSA & Te.H & Prunus avium L. & Pru.av & 1 & 1 & 0.62 & & 17.4 & & 10.0 & \\
\hline PAPI & Tr.H & Pterocarpus erinaceus Poir. & Pte.er & 86 & 4 & 0.83 & 3 & 19.3 & 4 & 5.6 & 6 \\
\hline PAPI & Tr.H & Pterocarpus macrocarpus Kurz & Pte.ma & 22 & 1 & 0.75 & 1 & 12.9 & 4 & 6.8 & 4 \\
\hline PAPI & Tr.H & Pterocarpus soyauxii Taub. & Pte.so & 170 & 16 & 0.77 & 9 & 18.3 & 15 & 5.2 & 14 \\
\hline PAPI & Tr.H & Pterocarpus tinctorius Welw. & Pte.ti & 6 & 1 & 0.93 & 2 & 14.0 & 7 & 6.8 & 9 \\
\hline ROSA & Te.H & Pyrus communis $\mathrm{L}$. & Pyr.co & 4 & 1 & 0.69 & 3 & 9.9 & 9 & 16.7 & 11 \\
\hline RHIZ & Tr.H & Rhizophora mangle $\mathrm{L}$. & Rhi.ma & 5 & 1 & 1.13 & 1 & 28.8 & 4 & 7.3 & 4 \\
\hline CAES & Tr.H & Scorodophloeus zenkeri Harms. & Sco.ze & 14 & 2 & 0.88 & 8 & 23.0 & 15 & 6.8 & 1 \\
\hline ROSA & Te.H & Sorbus domestica L. & Sor.do & 24 & 5 & 0.81 & 7 & 19.3 & 17 & 9.9 & 16 \\
\hline PAPI & Tr.H & Swartzia panacoco (Aubl.) Cowan & Swa.pa & 8 & 2 & 1.16 & 8 & 26.0 & 8 & 4.4 & 16 \\
\hline PAPI & Tr.H & Swartzia sp. & Swa.sp & 46 & 9 & 1.21 & 6 & 26.3 & 10 & 4.3 & 7 \\
\hline MELI & Tr.H & Swietenia macrophylla King & Swi.ma & 1 & 1 & 0.48 & & 20.7 & & 6.4 & \\
\hline BIGN & Tr.H & Tabebuia sp. & Tab.sp & 4 & 1 & 0.85 & 1 & 23.2 & 4 & 5.0 & 2 \\
\hline TAXA & $\mathrm{S}$ & Taxus baccata L. & Tax.ba & 25 & 5 & 0.64 & 6 & 11.1 & 17 & 10.0 & 8 \\
\hline CUPR & $\mathrm{S}$ & Thuja plicata D.Don & Thu.pl & 1 & 1 & 0.39 & & 19.5 & & 7.2 & \\
\hline RUTA & Tr.H & Zanthoxylum tsihanimposa H.Perr. & Zan.ts & 5 & 1 & 0.57 & 9 & 18.4 & 6 & 6.2 & 6 \\
\hline PAPI & Tr.H & $\begin{array}{l}\text { Zollernia ilicifolia (Brongn.) Vogel } \\
\quad \text { (or Swartzia } \mathrm{sp} . \text { ) }\end{array}$ & Zol.il & 6 & 1 & 1.06 & 4 & 21.4 & 6 & 5.1 & 10 \\
\hline PAPI & Tr.H & Zollernia paraensis Huber & Zol.pa & 14 & 1 & 1.16 & 4 & 21.1 & 7 & 5.8 & 7 \\
\hline
\end{tabular}

Botanical families are abbreviated by their four first letters

$S$ Softwoods, Te.H temperate hardwoods, $T r . H$ tropical hardwoods

Papilionoideae). This is probably due to the characteristic nature of their extractives, which strongly decrease $\tan \delta$ in several genera of this tribe (Yano et al. 1995; Brémaud et al. 2009, 2010b, 2011a; Traoré et al. 2010). It also probably explains the predominance of Dalbergieae in the xylophonemaking traditions of several continents (Brémaud 2012; Holz 1996; Traoré et al. 2010; Wegst 2006). Still from the point of view of utilisations, woods currently used for making Baroque to Modern violin bows are grouped at the far end of axis 1, i.e. they are mainly described by their high specific gravity and Young's modulus, along with a low $\tan \delta$ (Brémaud and Poidevin 2009; Wegst 2006). Other wood types in their vicinity could consequently be considered for this application: We have proposed several promising alternative species to bow makers for conducting practical trials (to be published).

Temperate hardwoods were generally rather distinct from tropical ones and dominated the lower left portion of the plane, i.e. woods characterised by their low modulus and high $\tan \delta$. Despite quite a wide range in specific gravity, no clear multi-variable distinction appeared within this category, which might however simply reflect the moderate number (12) of species under study.

The only characteristic shared by all softwoods was their lower than average specific gravity. Their ordinary wood types were poorly differentiated according to vibrational properties. Nevertheless, a distinct sub-group including "lutherie-grade" Picea abies was primarily governed by high specific modulus of elasticity combined to proportionally high loss properties (DS $\delta$ and $\left.E^{\prime \prime} / \gamma\right)$. This group also comprised other species of Pinaceae, suggesting that "resonance" Norway spruce may not be unique in its vibrational properties. Old growth Sitka spruce is often used as "alternative resonance wood" (e.g. Ono and Norimoto 1983; Bucur 2006), but the anatomical and chemical features of other woods of the same genus or even family could also lead to comparable properties (e.g. Brémaud 2012).

When confronting species diversity with intra-specific variability, the sapwoods of hardwood species (both 

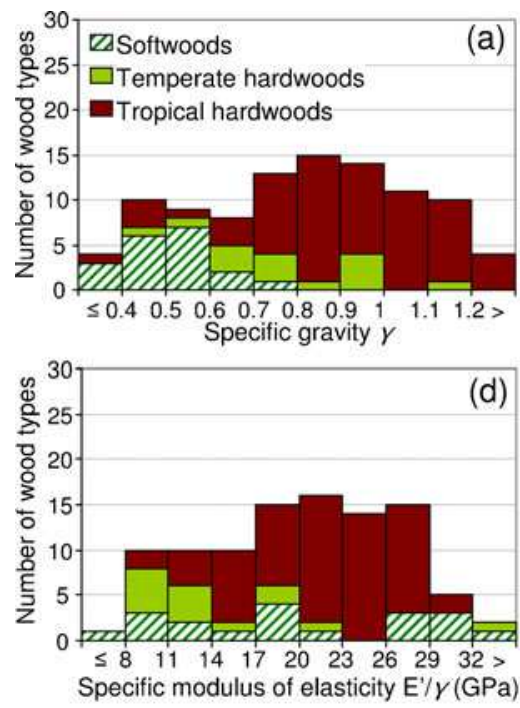
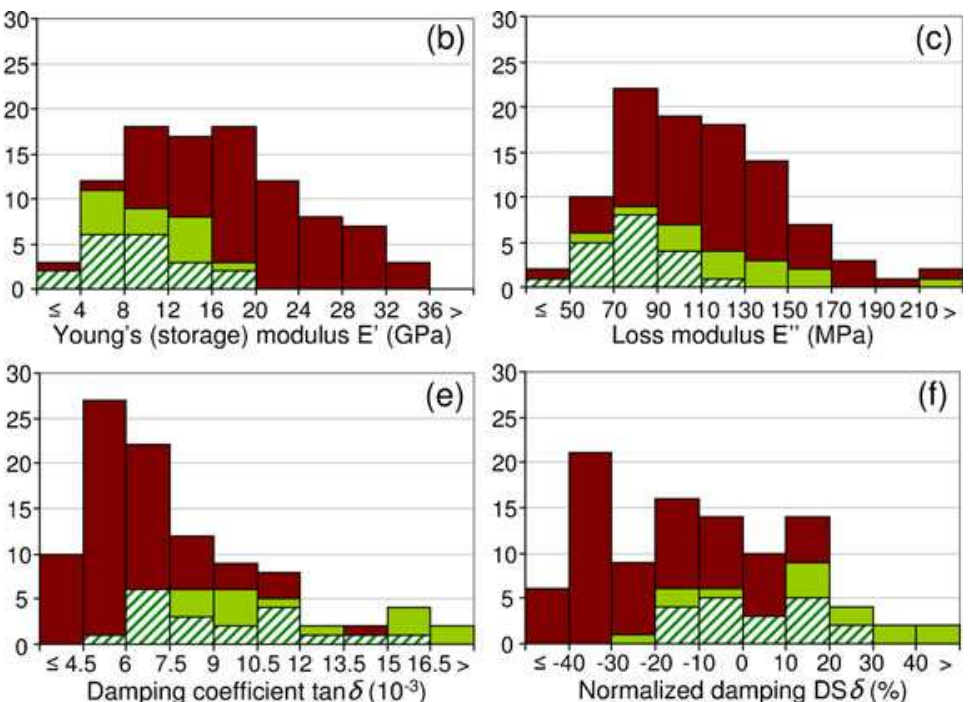

c)

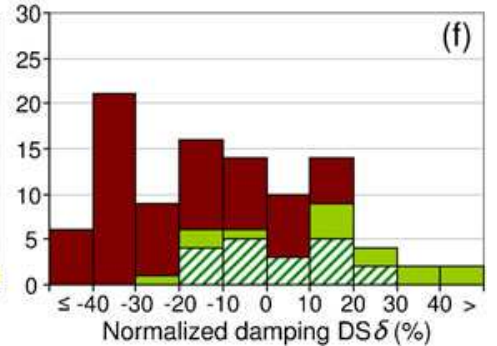

Fig. 9 Distributions of specific gravity (a), dynamic mechanical properties (b-e) and "normalised damping" (f) for the 98 wood types

temperate and tropical) covered a wide range of porosity and of $E^{\prime} / \gamma$. However, they were distributed orthogonally to the "viscosity" direction, which meant they were "neutral" regarding DS $\delta$ and $E^{\prime \prime} / \gamma$. Regarding reaction wood, compression woods formed a small group with very low $E^{\prime} / \gamma$ (as expected) and also slightly negative DS $\delta$ (Brémaud et al. 2011c). This group was not exceptional, however: It was close to normal wood of yew and to some temperate hardwoods. The only tension wood under study (poplar) was completely the reverse, with a very high $E^{\prime} / \gamma$ and also exceptionally high normalised damping.

The multi-variate confrontation of all wood types suggests that: (1) species diversity is the biggest source of variation in specific gravity and Young's modulus (with
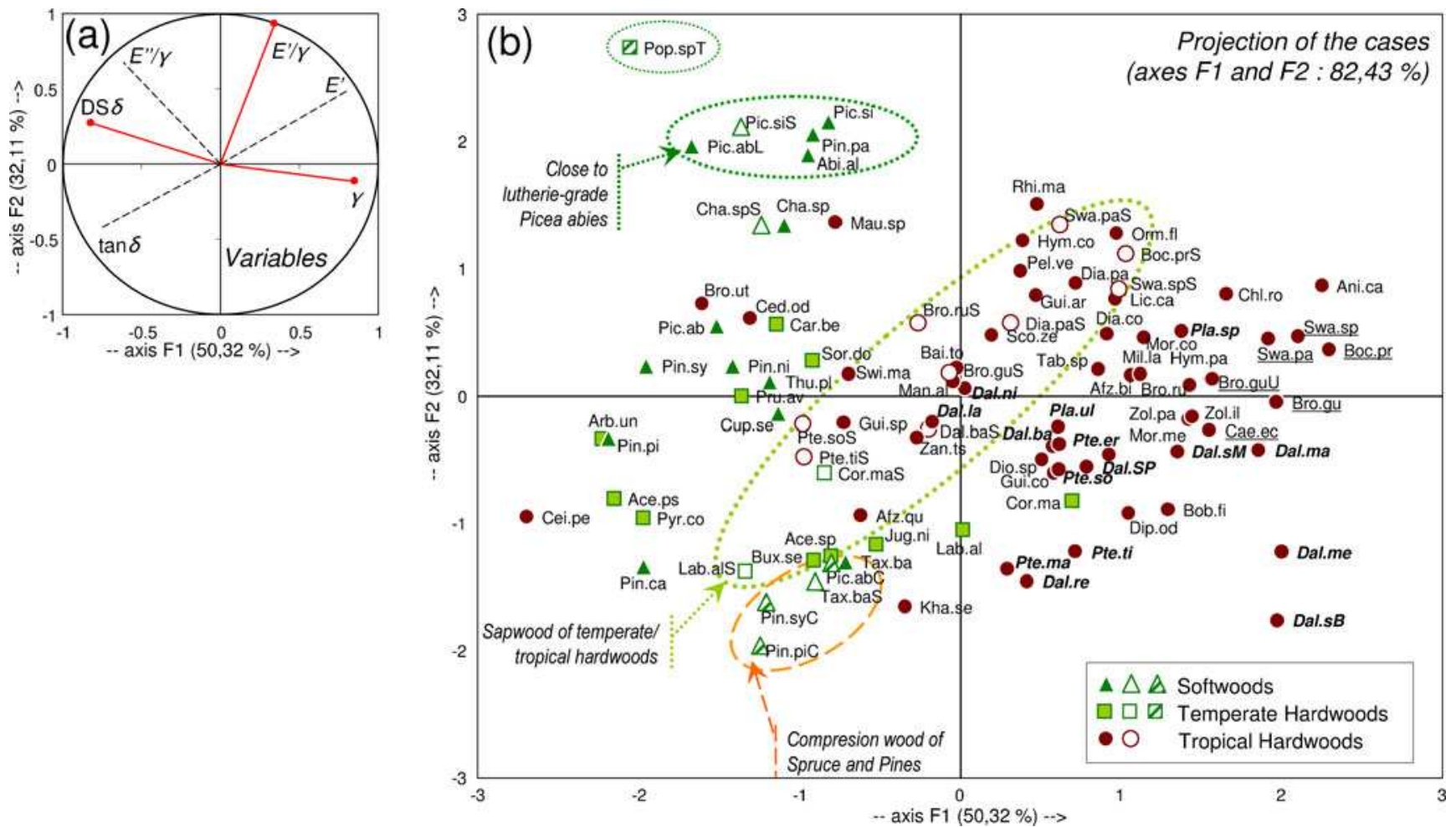

Fig. 10 Principal components analysis. a Projection of variables/ correlation circle. Solid lines Active variables $\left(\gamma, E^{\prime} / \gamma\right.$ and DS $\left.\delta\right)$; dashed lines inactive additional variables. b Projection of individuals.
Filled symbols Normal heartwood; open symbols normal sapwood; hatched symbols reaction wood. Labels: see Table 3; italics Dalbergieae; underscored woods used for violin bows 
reaction wood and heartwood formation as secondary effects); (2) reaction (compression or tension) wood formation is responsible for the most extreme differences in air-dry specific modulus of elasticity, ahead of the (nevertheless very large) inter-specific diversity; (3) taxonomy-related content in heartwood secondary metabolites appears to be the prominent source of diversity in normalised damping, although extreme variations in constitutive polymers (such as between normal and reaction woods) also play a significant role. These propertydependent responses to different sources of variability might have implications from a biomechanical point of view. Although present results concern air-dry wood properties, some tests on six tropical species suggest that little dispersed (but non-linear for damping) relationships can relate air-dry and green wood vibrational properties (Dlouhá 2009; Dlouhá et al. 2011).

From the viewpoint of acoustical end-uses, the present results allow better definition of the group characteristics of several preferred species for a given use in musical instruments making and to propose mechanically realistic alternative species. They also confirm that the traditional avoidance of sapwood in hardwoods and of compression wood in softwoods is justified, not only because of dimensional stability, aesthetical aspect or biological durability, but mostly so because of vibrational characteristics. The very wide range of wood material studied also allowed identification of secondary, little-known species with high potential interest in selected acoustical end-uses. However, it should be kept in mind that, in order to compare very different wood types in a rigorous way, a well-defined and generalised methodology is required, as demonstrated in this paper.

Acknowledgements Authors thank P. Cabrolier and J. Dlouhá for conducting some tests; P. Détienne (CIRAD xylarium) for wood identification; C. Daigremont and S. Lotte (CIRAD workshop) and instrument makers, for providing wood material; and N. Poidevin for testing "new" woods for violin bows.

Funding This work has been supported by CNRS and CIRAD in France and by JSPS in Japan.

\section{References}

Bordonné PA (1989) Module dynamique et frottement intérieur dans le bois. Mesures sur poutres flottantes en vibrations naturelles. $\mathrm{PhD}$, Institut National Polytechnique de Lorraine, Nancy

Brancheriau L, Baillères H (2002) Natural vibration analysis of clear wooden beams: a theoretical review. Wood Sci Technol 36:347-365

Brancheriau L, Kouchade C, Brémaud I (2010) Internal friction measurement of tropical species by various acoustic methods. J Wood Sci 56:371-379

Brémaud I (2006) Diversité des bois utilisés ou utilisables en facture d'instruments de musique. Doctorat, Université Montpellier II
Brémaud I (2012) Acoustical properties of wood in string instruments soundboards and tuned idiophones: biological and cultural diversity. J Acoust Soc Am 131. doi:10.1121/1.3651233

Brémaud I, Poidevin N (2009) Approches culturelles et mécaniques dans le choix des bois en facture: cas des archets anciens. In: 5 th Conference on Interdisciplinary Musicology, CIM09, 26-29 Octobre 2009, Paris, France

Brémaud I, Minato K, Thibaut B (2009) Mechanical damping of wood as related to species classification: a preliminary survey. In: Thibaut B (ed) 6th Plant Biomechanics Conference PBM09, 1621 November 2009, Cayenne, French Guyana. pp 536-542

Brémaud I, Cabrolier P, Gril J, Clair B, Gérard J, Minato K, Thibaut B (2010a) Identification of anisotropic vibrational properties of Padauk wood with interlocked grain. Wood Sci Technol 44:355-367

Brémaud I, Minato K, Langbour P, Thibaut B (2010b) Physicochemical indicators of the inter-specific variability in vibration damping of wood. Ann For Sci 67:707

Brémaud I, Amusant N, Minato K, Gril J, Thibaut B (2011a) Effect of extractives on vibrational properties of African Padauk (Pterocarpus soyauxii Taub.). Wood Sci Technol 45:461-472

Brémaud I, Gril J, Thibaut B (2011b) Anisotropy of wood vibrational properties: dependence on grain angle and review of literature data. Wood Sci Technol 45:735-754

Brémaud I, Ruelle J, Thibaut A, Thibaut B (2011c) Changes in viscoelastic vibrational properties between compression and normal wood: roles of microfibril angle and of lignin. Holzforschung (submitted)

Bucur V (2006) Acoustics of wood. Springer, Berlin

Chave J, Coomes D, Jansen S, Lewis SL, Swenson NG, Zanne AE (2009) Towards a worldwide wood economics spectrum. Ecol Lett 12:351-366

David B (1999) Caractérisations acoustiques de structures vibrantes par mise en atmosphère raréfiée. PhD, Université Paris 6

Détienne P, Chanson B (1996) L'éventail de la densité du bois des feuillus. Comparaison entre différentes régions du Monde. Bois For Trop 250:19-30

Dlouhá J (2009) Comportement viscoélastique longitudinal du bois vert: diversité et prédiction à long terme. Doctorat, Université Montpellier II

Dlouhá J, Alméras T, Clair B (2011) Representativeness of wood biomechanical properties measured after storage in different conditions. Trees. doi:10.1007/s00468-011-0636-9

Fukada E (1950) The vibrational properties of wood I. J Phys Soc Jpn 5:321-327

Hernandez RE (2007) Moisture sorption properties of hardwoods as affected by their extraneous substances, wood density, and interlocked grain. Wood Fiber Sci 39:132-145

Holz D (1996) Tropical hardwoods used in musical instruments - can we substitute them by temperate zone species? Holzforschung 50:121-129

Jones DIG (2001) Handbook of viscoelastic vibration damping. Wiley, Chichester

Kataoka A, Ono T (1975) The relations of experimental factors to the vibration and the measuring values of dynamic mechanical properties of wood. I. The experimental errors due to the measuring apparatus (in Japanese). Mokuzai Gakkaishi 21:543550

Kitahara R, Matsumoto T (1973) Mechanism of damping in wood (in Japanese). Mokuzai Gakkaishi 19:373-378

Kubojima Y, Ohtani T, Yoshihara H (2004) Effect of shear deflection on vibrational properties of compressed wood. Wood Sci Technol 38:237-244

Kubojima Y, Tonosaki M, Yoshihara H (2005) Effect of additional mass on the Young's modulus of a wooden beam. J Test Eval 33:278-282 
Matsunaga M, Sugiyama M, Minato K, Norimoto M (1996) Physical and mechanical properties required for violin bow materials. Holzforschung 50:511-517

Minato K, Sakai K, Matsunaga M, Nakatsubo F (1997) The vibrational properties of wood impregnated with extractives of some species of Leguminosae. Mokuzai Gakkaishi 43:10351037

Minato K, Konaka Y, Brémaud I, Suzuki S, Obataya E (2010) Extractives of muirapiranga (Brosimun sp.) and its effects on the vibrational properties of wood. J Wood Sci 56:41-46

Nakao T, Okano T, Asano I (1985) Theoretical and experimental analysis of flexural vibration of the viscoelastic Timoshenko beam. J Appl Mech 52:728-731

Obataya E, Norimoto M (1995) Acoustic properties of cane (Arundo donax L.) used for reeds of woodwind instruments I. The relationships between vibrational properties and moisture content of cane (in Japanese). Mokuzai Gakkaishi 41:289-292

Obataya E, Norimoto M, Gril J (1998) The effects of adsorbed water on dynamic mechanical properties of wood. Polymer 39:3059-3064

Obataya E, Umezawa T, Nakatsubo F, Norimoto M (1999) The effects of water-soluble extractives on the acoustic properties of reed (Arundo donax L.). Holzforschung 53:63-67

Obataya E, Ono T, Norimoto M (2000) Vibrational properties of wood along the grain. J Mater Sci 35:2993-3001

Obataya E, Minato K, Tomita B (2001) Influence of moisture content on the vibrational properties of hematoxylin-impregnated wood. J Wood Sci 47:317-321

Olsson AM, Salmén L (1992) Viscoelasticity of in situ lignin as affected by structure. Softwood vs. hardwood. In: ACS Symposium Series No 489, Viscoelasticity of Biomaterials. American Chemical Society, pp 133-143
Olsson A-M, Salmén L (1997) The effect of lignin composition on the viscoelastic properties of wood. Nord Pulp Pap Res J 3:140-144

Ono T, Kataoka A (1979) The frequency dependence of the dynamic Young's modulus and internal friction of wood used for the soundboard of musical Instruments II (in Japanese). Mokuzai Gakkaishi 25:535-542

Ono T, Norimoto M (1983) Study on Young's modulus and internal friction of wood in relation to the evaluation of wood for musical instruments. Jpn J Appl Phys 22:611-614

Ono T, Norimoto M (1984) On physical criteria for the selection of wood for soundboards of musical instruments. Rheol Acta 23:652-656

Sakai K, Matsunaga M, Minato K, Nakatsubo F (1999) Effects of impregnation of simple phenolics and natural polycyclic compounds on physical properties of wood. J Wood Sci 45:227-232

Sali S, Kopac J (1998) The influence of the different machining processes on the acoustic properties of wooden resonant boards. Catgut Acoust Soc J (II) 3:15-20

Sasaki T, Norimoto M, Yamada T, Rowell RM (1988) Effect of moisture on the acoustical properties of wood (in Japanese). Mokuzai Gakkaishi 34:794-803

Traoré B, Brancheriau L, Perré P, Stevanovic T, Diouf P (2010) Acoustic quality of vène wood (Pterocarpus erinaceus Poir.) for xylophone instrument manufacture in Mali. Ann For Sci 67:815

Wegst UGK (2006) Wood for sound. Am J Bot 93:1439-1448

Williamson BG, Wiemann MC (2010) Measuring wood specific gravity... Correctly. Am J Bot 97:519-524

Yano H (1994) The changes in the acoustic properties of Western red cedar due to methanol extraction. Holzforschung 48:491-495

Yano H, Kyou K, Furuta Y, Kajita H (1995) Acoustic properties of Brazilian rosewood used for guitar back plate (in Japanese). Mokuzai Gakkaishi 41:17-24 